\title{
CAG NEWS PAGE
}

\section{Meeting report: Research topics in gastrointestinal disease IX}

Organizing Committee:

Nicola Jones MD PhD FRCPC, University of Toronto, Toronto, Ontario

Ken Croitoru MD FRCPC, University of Toronto, Toronto, Ontario

Stephen Vanner MD MSc FRCPC Chair, CAG Research Committee,

Queens University, Kingston, Ontario

George Tolomiczenko MD, Executive Director of Research \& Scientific

Liaison, Crohn's and Colitis Foundation of Canada

Paul Belanger, Assistant Director, Institute of Nutrition Metabolism

and Diabetes, Canadian Institutes of Health Research

Louise Hope, CAG National Office

$\mathrm{T}$ he Canadian gastrointestinal (GI) research community is a world leader in advancing the understanding of many areas of physiology and pathophysiology relevant to GI disease. These highly successful research programs have created an excellent cohort of graduate and postgraduate research trainees involved in GI research at institutions across Canada. These trainees play an instrumental role in the discoveries and new knowledge that have emerged from their laboratories. Many of them are funded by the Canadian Association of Gastroenterology (CAG) in collaboration with the Canadian Institutes of Health Research (CIHR), several industry partners and the Crohn's and Colitis Foundation of Canada (CCFC).

To recognize the value of the Canadian GI trainees outstanding research contributions, and to promote and encourage the continued efforts of the graduate and postgraduate research trainees in basic and clinical sciences, the CAG, CCFC and CIHR, in conjunction with AstraZeneca Canada Inc, held the ninth symposium on Research Topics in Gastrointestinal Disease on October 16 to 18, 2009. The goal of this meeting was to provide research trainees with an opportunity to informally present their original research from diverse disciplines to their peers and to a selection of faculty from across Canada. In this forum, trainees actively participated in the discussions of papers in an open setting. This year's program consisted of a series of superb presentations describing cutting-edge research, with 40 podium scientific presentations of basic and clinical GI-related research covering GI development, pathogenesis of esophago-GI inflammation and healing, enteric microbiota and pathogens (including bacteria that promote cancer), gastric ulceration, enteric nerves, and epithelial transport and barrier function. New additions to the program this year included a research skills enhancement workshop focusing on developing a research proposal. Mr Paul Belanger presented 'How to develop a research proposal'. Armed with this knowledge, the trainees then developed their own proposals and presented them to the group in an entertaining and informative 'GI Research Idol' - adeptly judged by Drs Kelly 'Dawg' Burak, Michael 'your outfit really fits with the proposal' Beyak and Ken 'that was awful' Croitoru. In addition, a fiercely competitive 'GI Jeopardy', led by Dr Kelly Burak, kicked the program off.

As in previous years, a major success of the meeting was that it provided a venue in which trainees could meet their peers from

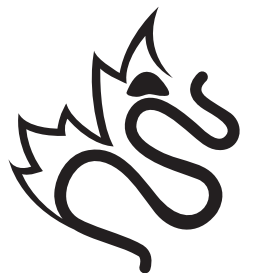

Canadian Association of Gastroenterology

En français voir page 797 across Canada, develop research skills and initiate collaborations, thus developing contacts for their future research career and the future of Canadian GI research. Participants rated the meeting good to excellent, and described the experience as insightful and a valuable opportunity for young researchers to exchange learning.

ACKNOWLEDGEMENTS: The organizers thank AstraZeneca Canada Inc, the CIHR-Institutes of Nutrition, Metabolism and Diabetes, and the CCFC for their generous support of this meeting, the ninth of its kind. In addition, we thank the invited faculty, Drs Emma Allen-Vercoe, Michael Beyak, Ron Bridges, Kelly Burak and Phil Sherman, for their commitment and valuable contributions to this meeting.

Participants and faculty in the ninth symposium on Research Topics in Gastrointestinal Disease, October 16 to 18, 2009 / Les participants et les professeurs au neuvième symposium sur les sujets de recherche en maladies gastro-intestinales, du 16 au 18 octobre 2009. Participants: Mohammad Al Beshir, Saskatoon, Saskatchewan; Vishal Avinashi, Toronto, Ontario; Aiping Bai, Winnipeg, Manitoba; Mohammad Bashashati, Calgary, Alberta; Misha Bawa, Calgary, Alberta; Joshua Bennitz, Toronto, Ontario; Meriem Boufassa, Laval, Quebec; Joannie Bruneau, Sherbrooke, Quebec; Deepti Chopra, Hamilton, Ontario; Maria Da Silva Martins, Montreal, Quebec; Shumona De, Bedford, Nova Scotia; Jakub Fichna, Calgary, Alberta; Jean-François Groulx, Sherbrooke, Quebec; Qingdong Guan, Winnipeg, Manitoba; Megan Himmel, Vancouver, British Columbia; Nathan Ho, Toronto, Ontario; Peter Horwich, Bedford, Nova Scotia; Humberto Jijon, Calgary, Alberta; Sari Kichler, London, Ontario; Vanessa Kissoon-Singh, Calgary, Alberta; Aifeng Lin, Toronto, Ontario; Bobbi-Jo Lowie, Hamilton, Ontario; Mark Lukewich, Kingston, Ontario; Faiza Maloum, Sherbrooke, Quebec; Jessica McClemens, Hamilton, Ontario; Julie McDonald, Guelph, Ontario; Daniel Mulder, Kingston, Ontario; Simrin Nagpal, Kingston, Ontario; Michael Peplowski, Calgary, Alberta; Sébastien Roy, Sherbrooke, Quebec; Ho Pan (Andy) Sham, Vancouver, British Columbia; Natasha Singh, Toronto, Ontario; David Smyth, Calgary, Alberta; Emily Stern, Kingston, Ontario; Stéphanie St-Jean, Sherbrooke, Quebec; Jaclyn Strauss, Guelph, Ontario; Shivangi Trivedi, Toronto, Ontario; Elizabeth Trusevych, Kingston, Ontario; Ekaterina Yurchenko, Montreal, Quebec; and Julie Zhu, Edmonton, Alberta. Faculty / Professeurs: Dr Emma Allen-Vercoe, Guelph, Ontario; Dr Michael Beyak, Kingston, Ontario; Mr Paul Belanger, Ottawa, Ontario; Dr Ron Bridges, Calgary, Alberta; Dr Kelly Burak, Calgary, Alberta; Dr Ken Croitoru, Toronto, Ontario; Dr Nicola Jones, Toronto, Ontario; Dr Phil Sherman, Toronto, Ontario; and Dr Stephen Vanner, Kingston, Ontario.

The CAG is proud to acknowledge its Benefactor Corporate Sponsors:

Abbott Canada
AstraZeneca Canada Inc
Axcan Pharma Inc

Schering-Plough Canada Inc

UCB Pharma Inc 


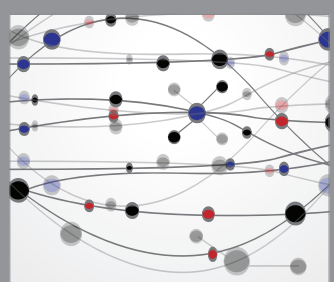

The Scientific World Journal
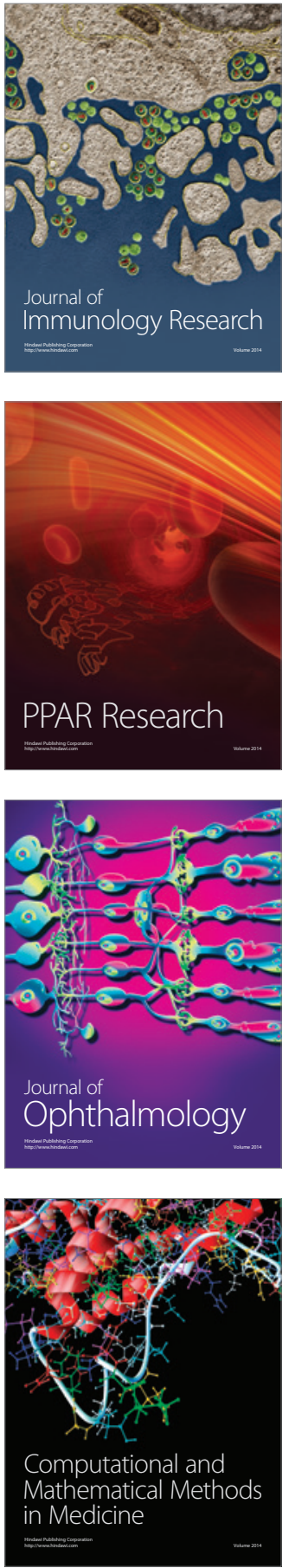

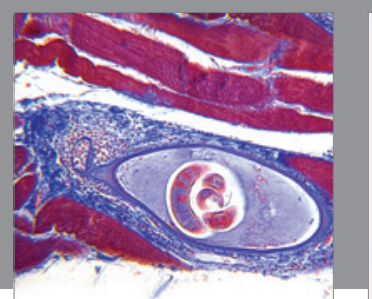

Gastroenterology Research and Practice

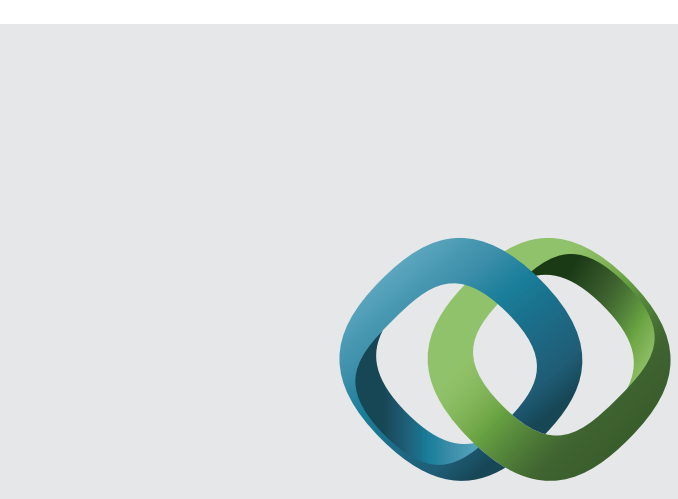

\section{Hindawi}

Submit your manuscripts at

http://www.hindawi.com
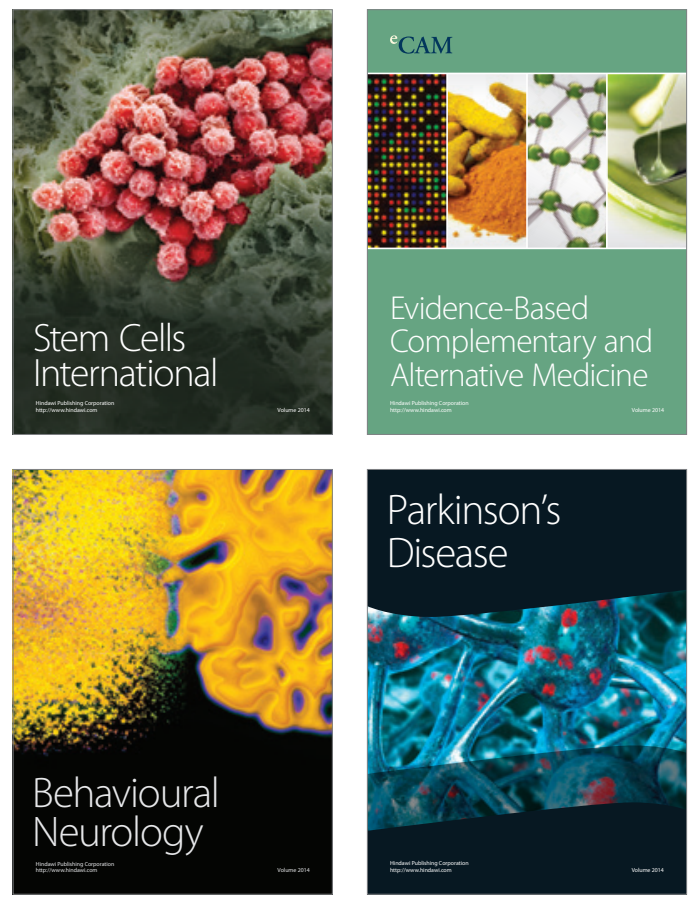
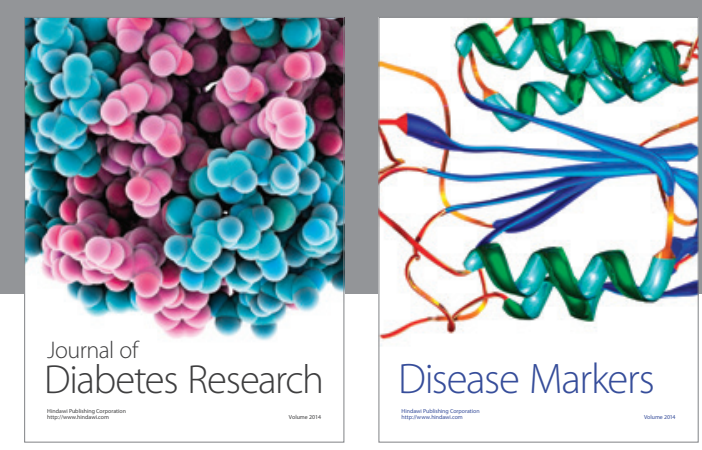

Disease Markers
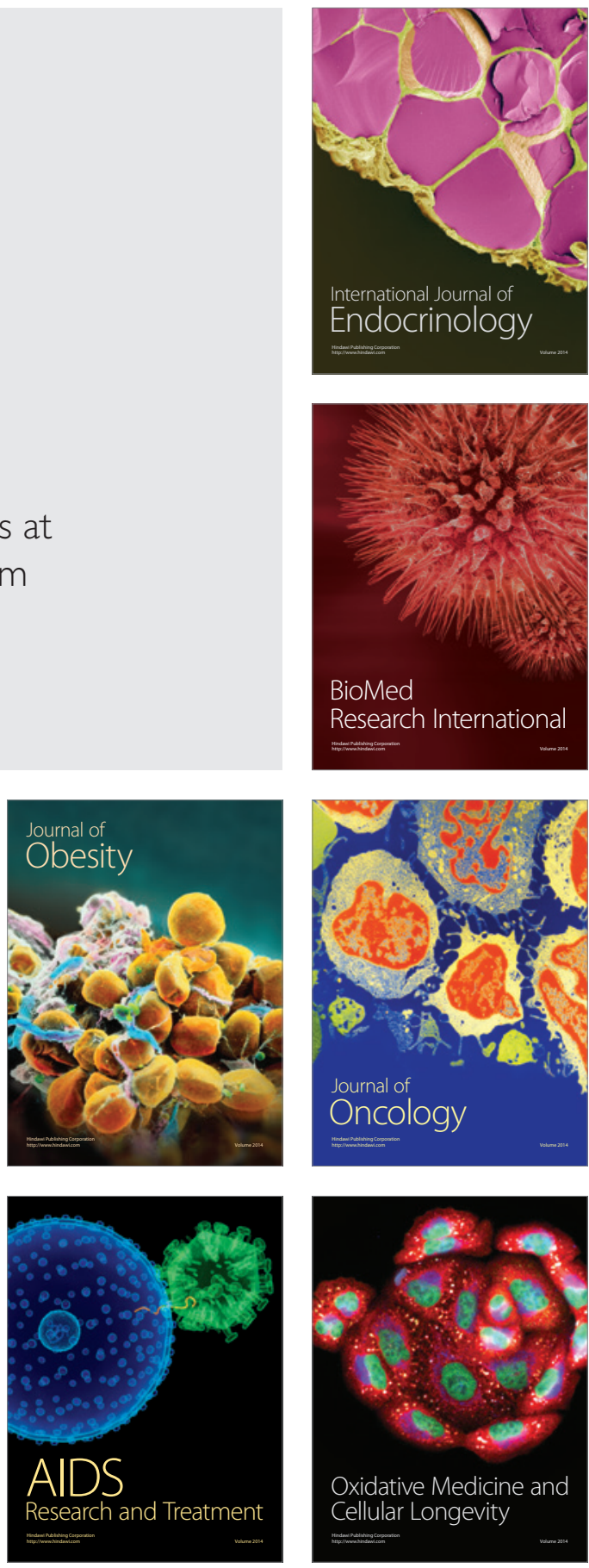